\title{
Preface: climate change proof flood risk management
}

\author{
Frans Klijn ${ }^{1} \cdot$ Bruno $\mathrm{Merz}^{2} \cdot$ Edmund C. Penning-Rowsell ${ }^{3}$. \\ Zbigniew W. Kundzewicz ${ }^{4,5}$
}

Published online: 3 July 2015

(C) Springer Science+Business Media Dordrecht 2015

\section{Climate change and flood risk-setting the scene}

It is widely being recognized that climate change is happening. Anthropogenic emissions of greenhouse gases cause warming of the atmosphere and oceans. The resulting changes in the climate system and water cycle are unequivocal and manifest themselves in sea level rise and an increasing likelihood of extreme weather worldwide, evidenced by the increasing frequency of occurrence of hurricanes, tornados, extreme rainfall and heat waves. Moreover, these extreme events affect more and more people and have increasingly larger economic consequences due to demographic and economic developments, because there is a massive migration towards river floodplains, deltas and coastal plains as these provide the largest opportunities for economic development. The records of flood- and drought-related disasters in the past decades leave no doubt about the combined consequences of these geo-ecological and socio-economic developments; disaster risk increases.

Mitigation of and adaptation to climate change are complementary strategies for reducing and managing the risks related to climate change. Effective global climate change mitigation is urgently needed and may also be the most efficient strategy as demonstrated by Stern (2006), but it is not in sight yet. Despite all the international policy efforts (including 20 annual conferences of parties of the United Nations Framework Convention on Climate Change, UNFCCC, gathering more than 10,000 participants each), emissions and atmospheric concentrations of greenhouse gases have been growing to unprecedented levels. Mitigation would depend on concerted global action of large players such as China and the USA, the countries with the largest carbon dioxide

Frans Klijn

Frans.Klijn@deltares.nl

Deltares, Delft, The Netherlands

2 Helmholtz-Centre Potsdam, GFZ German Research Centre for Geosciences, Potsdam, Germany

3 Flood Hazard Research Centre, Middlesex University, London, UK

4 Institute for Agricultural and Forest Environment, Polish Academy of Sciences, Warsaw, Poland

5 Potsdam Institute for Climate Impact Research, Potsdam, Germany 
emissions. Moreover, there is increasing recognition that even a rigorous mitigation is unlikely to put a halt to the warming in a short term, due to the inertia of the climate system. Therefore, vulnerable countries and regions tend to turn towards adapting to those global developments which they consider to be beyond their influence. Adapting to climate change is a considerable challenge, requiring people to not only take into account the past climate variability but also to anticipate on future climate variability and connected risks by a smart use of climate projections, for example by considering plausible future scenarios.

During the last decades, many countries started questioning which impacts of global change might be key to their specific situation. Flooding has turned out to be the most widespread. Large, destructive floods have occurred in Europe several times in the last two decades, for instance in 1995, 1997, 2000, 2002 (with an all-time record-breaking flood damage in many countries in August 2002), 2007, 2010, 2013 and 2014. The overview of impacts collected in the Fifth Assessment Report by the Intergovernmental Panel on Climate Change (IPCC 2014) triggered a lot of societal debate and political action in this respect, although the scientific world was naturally already onto it since it provided the national and regional information for the IPCC report.

Worldwide, about 800 million people currently live in flood-prone areas and about 70 million of those are, on average, affected by flooding each year. Global economic losses caused by floods amount to tens of billions of dollars annually. The numbers of fatalities and relative economic losses (expressed as a proportion of gross domestic product) are typically larger in developing countries than in developed countries, which have better warning systems in place, can afford better protection, and have a larger recovery capacity. The highest relative share of an economy exposed to floods is Cambodia, while Bangladesh is the country with the largest number of people exposed to floods, both in absolute and relative terms (Kundzewicz et al. 2014).

Present climate projections show that flood hazard is likely to increase over about half the globe. At a site of concern, a current 100-year river flood (river flow exceeded once every 100 years on average) may become a 50-year flood within a few decades. Despite the inherent uncertainty of model-based projections, such information could be important for decisionmakers and the potentially affected people. Changes in flood probability mean that existing flood defences may not provide the protection that is expected. They may need to be strengthened.

However, due to the uncertainty of climate projections and the difficulties in downscaling to regional catchment scales, it is currently not easy to devise a rigorous, scientifically sound procedure for redefining design floods. The dilemma 'adapt to what exactly?' then comes about. For the time being, it is therefore often recommended to adjust design floods by using a safety factor or climate-change robustness factor, thus applying a precautionary principle. But other approaches are being proposed, such as exploratory modelling for alternative future scenarios, robust decision making, pathway planning, etc. (Klijn et al. 2015a).

Meanwhile, a practical approach could involve that a society should not lose focus on the things we already know about flood risks and how to cope with those. Coping better with existing extremes augurs better for a more demanding, yet uncertain, future. And coping with extremes and climate variability is inherent to flood risk management. Flood risk is a function of the probability of floods, their characteristics in terms of extent, depth, etc., exposure of people and assets in places that are affected and vulnerability (predisposition to be adversely affected) of human society and natural ecosystems. Risk is often quantified as the probability 
of occurrence of hazardous events multiplied by the impacts that ensue if these events occur (IPCC 2012).

There exists a roster of measures and strategies for reducing flood losses. A category of measures aimed at keeping water away from people includes flood defences, as well as flood flow improvement and retention. This is often addressed as flood mitigation, including flood protection and flood management. Another strategy - flood risk prevention - aims at keeping people and wealth away from water. This is especially relevant in the context of adaptation, as many studies indicate that increasing exposure of people and assets, rather than anthropogenic climate change, is responsible for the past increase in flood losses (Kundzewicz et al. 2014). Still, we have to be aware that there will always exist a possibility of a coincidence of flooding and a considerable damage potential at the same time and place. Hence, we have to consider the residual risk in all situations where attempts to keep water away from people and to keep people and wealth away from water may fail.

By first acknowledging that any protection system may fail, we should perhaps refrain from striving to build a fail-safe system. Instead, we might opt for a system that would fail in a safe way (safe-fail) and easily recover after failure. This is the essence of building resilience into engineered systems. Since a flood protection system guaranteeing absolute safety is an illusion, a change of paradigm may be needed; it is necessary to be aware of the possibility of floods.

\section{Deltas: focal points of global change challenges}

Especially in low-lying river deltas, a number of climate change issues come together, such as increasing flood risk and decreasing freshwater availability. This is caused by the interaction of a number of processes: sea level rise, sedimentation in river floodplains and subsidence of the protected areas that make deltas increasingly flood-prone (Syvitski et al. 2009), whereas migration to these prosperous areas and their further development make them increasingly vulnerable (Jongman et al. 2012). In the dry season, the combination of reduced river discharges and higher sea level aggravates the external salinization of surface water bodies and groundwater resources. Obviously, there are large differences between river deltas worldwide, depending on the climate zone and the degree of development. But at the same time, the adaptation challenges are quite similar, allowing lessons to be learnt from specific cases and to be shared among peers (Bucx et al. 2014).

The delta of the Rhine and Meuse rivers forms the majority of the Netherlands, a country which uses to boast of its being the best protected delta in the world and determined to remain so. More than $55 \%$ of the country area is flood-prone, and $40 \%$ lies below sea level as a consequence of many centuries of draining. The majority of the 16.8 million Dutch people live in this densely populated flood-prone area which is also the economic heart of the country. This provides sufficient reasons to consider flood risk management a national issue and not something which regions or communities (as in Germany) or individuals and insurance companies (like in the UK) should be primarily held responsible for. And obviously, there is also a good reason to take sea level rise and other impacts of global change very seriously indeed.

The Netherlands has an international reputation when it comes to managing flood risks or rather protecting against floods. The country's traditional calling cards are the Afsluitdijk and Delta Works, but these have recently been complemented by nature-based 'soft' solutions such 
as the Room for the River programme (Klijn et al. 2013) and sand nourishments along the coast (e.g., the Sand Engine project). The reputation of the Netherlands not only relies on its technical accomplishments (Eastern Scheldt barrier and Maeslant barrier), but also on how research (Delft, Wageningen, Utrecht and Amsterdam research institutes and universities) and practice (the Ministry of Infrastructure and Environment and the water boards which cover the entire territory of the Netherlands) influence one another and work together. And on the way in which public authorities, knowledge institutions and local stakeholders arrive at joint solutions with ample public support by being committed to sharing knowledge and participatory planning.

But what about anticipating climate change and adaptation policy? The Netherlands has paid attention to climate change for decades already, but as in most other countries, the focus has long been on understanding and quantifying the problem. Only recently, triggered by disasters elsewhere in the world and articulated in research programmes (Kwadijk et al. 2006) and policy recommendations (Delta Committee 2008) has the attention shifted away from mere understanding towards action planning. This shift involves a transition towards anticipating instead of reacting (anticipatory versus reactive adaptation), whereas at the same time, it is being questioned whether or not a complete change of flood risk management strategy may be needed or simply a broader portfolio of measures and policy instruments. The latter is needed because the Netherlands' government has explicitly acknowledged that flood risk can never be reduced to zero. Some residual risk will always remain.

\section{Perspective on flood risk management from the knowledge for climate programme}

The present special issue of the journal Mitigation and Adaptation Strategies for Global Change is dedicated to flood risk management in view of global change. The interdisciplinary material of this special issue originates from the work carried out within a major Netherlands' programme - Knowledge for Climate (2007-2014). The research in this programme, financed by the Netherlands' Ministry of Infrastructure and the Environment, with co-funding from local and regional stakeholders and from the research institutes participating in the consortium, was executed by research institutions and universities from the Netherlands but also by two foreign partners, from Germany and the UK. The programme had focus on the practical drafting of both local and regional adaptation strategies, but also on supportive applied scientific research. In parallel, a national policy programme was initiated in the Netherlands in 2010, addressing the key challenge to ensure a sustainable future development in view of global change, the Delta Programme. In 2014, this programme recommended on a number of key decisions (delta decisions) to constitute a long-term anticipatory policy characterized by mainstreaming climate adaptation into the more conventional policy fields of water management and spatial planning. A key concept in this policy is Adaptive Delta Management, jointly developed by the Delta Programme and supportive research exemplified by, among others, the Knowledge for Climate programme. In its concretization, the research programme could thus work on real cases, whereas the policy programme could apply the latest scientific insights.

The Knowledge for Climate programme (www.knowledgeforclimate.nl) focussed on regional hotspots and distinguished eight research themes, one being climate-change proof flood risk management - the theme reported in this special issue. The idea to make this special issue came as a recommendation from the international review panel which scrutinized the 
Knowledge for Climate programme when it was halfway. This panel examined the till then dispersed knowledge generated and called for comprehensive reporting of the key findings in a prestigious international periodical with high impact.

Obviously, flood risk management always has to deal with the uncertainties of weather conditions: rainfall intensities, storm surges, extreme river discharges etc. This kind of uncertainties is usually coped with by taking a risk-based perspective. Global change adds another dimension of uncertainties to it, as climate projections may not agree on the rate of change, and sometimes not even on the direction of change. Then, a risk-based approach alone may not suffice. Questions may arise about the sustainability of management strategies in the long term or about possible policy tipping points because strategies may become unaffordable or technically impossible to sustain. And the identification of the most appropriate timing of implementation of counteracting measures becomes an issue, along with questions about an adaptation pathway that gives the least chance of disastrous failure.

These issues are tackled in the first full paper of this special issue (Klijn et al. 2015a), which primarily sets the scene and discusses the key concepts. It also introduces the other papers and explains how they relate to the conceptual framework; therefore, we shall abstain from elaborating on the individual contributions in this foreword. Consecutive papers focus on specific flood risk management-related subjects, namely on the reliability of risk assessments (De Moel et al. 2015) which is a prerequisite for decision making, and on methods for riskbased standard setting for flood protection instead of using design floods plus some extra freeboard (Tsimopoulou et al. 2015). The next two papers address the question how much flood protection can be achieved by deploying nature-based measures, such as sand nourishments to the exposed sandy coast (Keijsers et al. 2014) and promoting the development of salt marshes in more sheltered coastal environments (Van Loon-Steensma 2015). The following paper (Nillesen and Kok 2015) addresses the design of flood defences not only for the sake of flood protection, but also in view of their potential positive side-effects for everyday use. This exemplifies the added value of approaching adaptation planning from an interdisciplinary perspective.

The first five papers in this special issue thus breath the Netherlands' orientation towards flood protection resulting from a predominantly top-down planning approach and implementation by well-established institutions, with the water boards being among the oldest democratic institutions of modern civilization and with the national Rijkswaterstaat as an inheritance from historic French centralistic domination and funded collectively by tax payers who acknowledge the advantages of this collective approach. The two papers that follow, in contrast, are first authored by colleagues from Germany (Kreibich et al. 2015) and the UK (Penning-Rowsell and Priest 2014). These slightly counterbalance the Netherlands' cultural bias towards flood protection, which may easily result in over-engineering. These papers address the effectiveness and potential of measures at the household level (Kreibich et al. 2015), respectively issues about who gains and who loses in an individualistic market-oriented approach to coping with flood risk with a large role for the insurance industry as we find in the UK (Penning-Rowsell and Priest 2014).

The final paper in this special issue (Klijn et al. 2015b) is about how to select the most desirable strategic alternative for adaptive flood risk management from a sustainability point of view. It looks at different portfolios of mainly technical measures and discusses whether societal cost-benefit analysis should not be complemented by robustness analysis in order to achieve flood risk systems that are safe-fail. 
This special issue complements an earlier special issue of Mitigation and Adaptation Strategies for Global Change on adaptation to extreme weather events in Europe under global and climate change (cf. Mechler and Kundzewicz 2010; Lugeri et al. 2010; Kundzewicz et al. 2010). The topic of flood risk management practice and planning in view of global changes, as tackled in this special issue, is also germane to other papers in this journal, such as Refsgaard et al. (2013), Botzen et al. (2013), Lacerda et al. (2014), Lin et al. (2014), and Razafindrabe et al. (2014).

Altogether we hope these papers may inspire the concerned readership, in similar as well as different cultural, socio-economic and geo-ecological settings. Not as examples to be followed headlong, but rather as inspiration to try other perspectives in search of context-specific adaptation strategies, aimed at realising almost globally shared values.

\section{References}

Botzen WJW, Aerts JCJH, van den Bergh JCJM (2013) Individual preferences for reducing flood risk to near zero through elevation. Mitig Adapt Strat Glob Chang 18:229-244

Bucx T, van Driel W, De Boer H, Graas S, Langenberg VT, Marchand M, Van de Guchte C (2014) Comparative assessment of the vulnerability and resilience of deltas — extended version with 14 deltas — synthesis report. Delta Alliance report number 7. Delta Alliance International, Delft/Wageningen, the Netherlands

Delta Committee (2008) Working together with water. A vital country builds its future. The Hague (in Dutch)

De Moel H, Jongman B, Kreibich H, Merz B, Penning-Rowsell EC, Ward Ph (2015) Flood risk assessments at different spatial scales. Mitig Adapt Strat Glob Chang. doi:10.1007/s11027-015-9654-Z

IPCC (2012) Managing the risks of extreme events and disasters to advance climate change adaptation. In: Field CB, Barros VR, Stocker TF, Qin D, Dokken DJ, Ebi KL, Mastrandrea MD, Mach KJ, Plattner G-K, Allen SK, Tignor M, Midgley PM (eds) A special report of working groups I and II of the intergovernmental panel on climate change. Cambridge University Press, Cambridge

IPCC (2014) Climate change 2014: synthesis report. In: Core Writing Team, Pachauri RK, Meyer LA (eds) Contribution of working groups I, II and III to the fifth assessment report of the intergovernmental panel on climate change. IPCC, Geneva

Jongman BP, Ward J, Aerts JCJH (2012) Global exposure to river and coastal flooding: long term trends and changes. Glob Environ Chang 22(4):823-835

Keijsers JGS, Giardino A, Poortinga A, Mulder JPM, Riksen MJPM, Santinelli G (2014) Adaptation strategies to maintain dunes as flexible coastal flood defense in The Netherlands. Mitig Adapt Strat Glob Chan. doi:10.1007/s11027-014-9579-y

Klijn F, De Bruin D, De Hoog M, Jansen S, Sijmons D (2013) Design quality of room-for-the-river measures in the Netherlands: role and assessment of the Quality Team (Q-team). J River Basin Manag 11:287-299

Klijn F, Kreibich H, de Moel H, Penning-Rowsell EC (2015a) Adaptive flood risk management planning based on a comprehensive flood risk conceptualisation. Mitig Adapt Strat Global Chan. doi:10.1007/s11027-0159638-z

Klijn F, Mens MJP, Asselman NEM (2015b) Flood risk management for an uncertain future: robustness and economic efficiency perspectives compared for the Meuse River (Netherlands). Mitig Adapt Strat Glob Chang. doi:10.1007/s11027-015-9643-2

Kreibich H, Bubeck Ph, Van Vliet M, De Moel H (2015) A review of damage-reducing measures to manage fluvial flood risks in a changing climate. Mitig Adapt Strat Glob Chang. doi:10.1007/s11027-014-9629-5

Kundzewicz ZW, Lugeri N, Dankers R, Hirabayashi Y, Döll P, Pińskwar I, Dysarz T, Hochrainer S, Matczak P (2010) Assessing river flood risk and adaptation in Europe-review of projections for the future. Mitig Adapt Strat Glob Chang 15(7):641-656

Kundzewicz ZW, Kanae S, Seneviratne SI et al (2014) Flood risk and climate change: global and regional perspectives. Hydrol Sci J 59(1):1-28

Kwadijk J, Klijn F, van Drunen J (2006) Climate durability of the Netherlands: benchmark assessment. Delft Hydraulics report Q4183, Delft (in Dutch)

Lacerda GBM, Silva C, Pimenteira CAP, Kopp RV Jr, Grumback R, Rosa LP, de Freitas MAV (2014) Guidelines for the strategic management of flood risks in industrial plant oil in the Brazilian coast: adaptive measures to the impacts by relative sea level rise. Mitig Adapt Strat Glob Chang 19:1041-1062 
Lin BB, Bing KY, Inman M, Chi-Hsiang W, Tapsuwan S, Xiaoming W (2014) Assessing inundation damage and timing of adaptation: sea level rise and the complexities of land use in coastal communities. Mitig Adapt Strat Glob Chang 19:551-568

Lugeri N, Kundzewicz ZW, Genovese E, Hochrainer S, Radziejewski M (2010) River flood risk and adaptation in Europe - assessment of the present status. Mitig Adapt Strat Glob Chang 15(7):621-639

Mechler R, Kundzewicz ZW (2010) Assessing adaptation to extreme weather events in Europe - editorial. Mitig Adapt Strat Glob Chang 15(7):611-620

Nillesen AL, Kok M (2015) An integrated approach to flood risk management and spatial quality for a Netherlands' river polder area. Mitig Adapt Strat Glob Chang, in press

Penning-Rowsell EC, Priest SJ (2014). Sharing the burden of increasing flood risk: who pays for flood insurance and flood risk management in the United Kingdom. Mitig Adapt Strat Glob Chang. doi:10.1007/s11027014-9622-Z

Razafindrabe BHN, Kada R, Arima M, Inoue S (2014) Analyzing flood risk and related impacts to urban communities in central Vietnam. Mitig Adapt Strat Glob Chang 19:177-198

Refsgaard JC, Arnbjerg-Nielsen K, Drews M, Halsnæs K, Jeppesen E, Madsen H, Markandya A, Olesen JE, Porter JR, Christensen JH (2013) The role of uncertainty in climate change adaptation strategies - a Danish water management example. Mitig Adapt Strat Glob Chang 18:337-359

Stern N (2006) Stern review on the economics of climate change (pre-publication edition). Executive summary. HM Treasury, London

Syvitski JPM, Kettner AJ, Overeem I, Hutton EWH, Hannon MT, Brakenridge GR, Day J, Vörösmarty C, Saito Y, Giosan L, Nicholls RJ (2009) Sinking deltas due to human activities. Nat Geosci 2:681-686

Tsimopoulou V, Kok M, Vrijling J (2015) Economic optimization of flood prevention systems in the Netherlands. Mitig Adapt Strat Glob Chang.doi:10.1007/s11027-015-9634-3

Van Loon-Steensma JM (2015) Salt marshes to adapt the flood defences along the Dutch Wadden Sea coast. Mitig Adapt Strat Glob Chang. doi:10.1007/s11027-015-9640-5 